\title{
An Experimental Investigation on the Mechanical Properties including Strength and Flexural Toughness of Mortar Reinforced with Steel-Carbon Hybrid Fibers
}

\author{
Gwang-Hee Heo, ${ }^{1}$ Jong-Gun Park $\mathbb{D}^{1},{ }^{2}$ Dong-Ju Seo, ${ }^{3}$ Hyung-Min Jun, ${ }^{3}$ and Sung-Gon Koh ${ }^{4}$ \\ ${ }^{1}$ Department of International Civil and Plant Engineering, Konyang University, 121 Daehak-ro, Nonsan-si, Chungnam-do, \\ Republic of Korea \\ ${ }^{2}$ Public Safety Research Center (PSRC), Konyang University, 121 Daehak-ro, Nonsan-si, Chungnam-do, Republic of Korea \\ ${ }^{3}$ Department of Disaster and Safety Engineering, Konyang University, 121 Daehak-ro, Nonsan-si, Chungnam-do, \\ Republic of Korea \\ ${ }^{4}$ Department of Cadastre and Civil Engineering, Jeonju Vision College, 235 Cheonjam-ro, Wansan-gu, Jeonju-si, Jeonbuk-do, \\ Republic of Korea
}

Correspondence should be addressed to Jong-Gun Park; 2630@hanmail.net

Received 16 June 2021; Accepted 18 August 2021; Published 7 September 2021

Academic Editor: Cai Gaochuang

Copyright (c) 2021 Gwang-Hee Heo et al. This is an open access article distributed under the Creative Commons Attribution License, which permits unrestricted use, distribution, and reproduction in any medium, provided the original work is properly cited.

\begin{abstract}
This paper presents the results of an experimental investigation conducted to evaluate the mechanical properties, including strength and flexural toughness of hybrid fiber-reinforced mortar (FRM) containing various combinations of steel and carbon fibers with different material characteristics. The mortar specimens were mixed with steel and carbon fibers in the mix proportions of $100+0 \%$, $75+25 \%, 50+50 \%, 25+75 \%$, and $0+100 \%$ by volume at a total volume fraction of $1.0 \%$. The flexural performance (flexural strength and toughness) of the mortar specimens was obtained using the third-point loading arrangement stipulated in the test methods of ASTM C 1609/C 1609/M and KS F 2566. In addition, compressive strength was also measured according to the KS F ISO 679 test method. Their mechanical properties were examined and compared with plain mortar (PM) at the age of 28 days. The test results showed the highest compressive and flexural strengths in the hybrid FRM reinforced with $75 \%$ steel fibers $+25 \%$ carbon fibers, confirming the synergistic reinforcing effect of the steel and carbon hybrid fibers. However, the hybrid FRM reinforced with 50\% steel fibers $+50 \%$ carbon fibers has obtained slightly low flexural strength but owned the highest flexural toughness and hence can be judged as the most appropriate combination to be employed in hybrid FRM to improve the flexural toughness. Moreover, the fractured FRM surface was also observed via scanning electron microscopy (SEM) after platinum coating in vacuum. These results would be of great help in establishing the microstructural mechanism of hybrid reinforcing fibers in the cement matrix.
\end{abstract}

\section{Introduction}

Cement-based composites, due to their excellent compressive strength, have been widely used worldwide as major construction materials for civil engineering structures and buildings [1-3]. However, cement-based composite materials have two well-known weaknesses: they not only are vulnerable to the flexural-tensile strength but also have low deformation performance [4-7]. To compensate for these shortcomings, fiber-reinforced cement composites (FRCC), in which discontinuous and chopped fiber materials are irregularly dispersed in cement composites, have been developed and are increasingly applied [8-14].

Fibers employed in FRCC are classified into microfibers and macrofibers according to their size (length and diameter). Generally, microfibers have a length of 5 to $10 \mathrm{~mm}$ and a diameter of 7 to $30 \mu \mathrm{m}$, and depending on the material, they are classified into carbon fibers [15-19], glass fibers [20-22], and basalt fibers [23-25]. On the other hand, macrofibers are $25 \sim 80 \mathrm{~mm}$ long and $0.2 \sim 0.8 \mathrm{~mm}$ in 
diameter, and they are divided into steel fiber $[6,26-30]$ and synthetic fiber [31-36] by size. The microfiber is stronger and stiffer and provides reasonable first crack strength and ultimate strength, whereas the macrofiber is relatively flexible and leads to improved toughness and strain capacity in postcracking zone.

Figure 1 shows structures of large and short fibers controlling the crack propagation in a cement matrix [37-39]. As shown in Figure 1, microfibers can greatly improve the flexural strength, short and soft microfibers control microcracks, and relatively large and strong macrofibers more effectively control macrocracks. It is expected that the flexural and tensile performance of FRCC will be improved.

In general, however, FRCC has been used limitedly with single fibers, and various studies are being carried out on hybrid FRCC that maximizes the effects that a single fiber cannot by mixing two or more types of fibers with different material characteristics in an appropriate ratio [40-46]. In case of a hybrid fiber reinforcement with different material characteristics, effects that cannot be expected with a single fiber reinforcement only can be obtained, which not only controls cracking effectively but also increases the strength and flexural toughness at the same time, thereby improving mechanical performance. Mortars reinforced with steelcarbon hybrid fibers are effective in terms of increasing strength and flexural toughness, but information on the proper mixing ratio of these fibers is still too limited. Currently, hybrid fiber-reinforced mortar (FRM) is mainly applied to concrete structures using fibers whose fiber mixing ratio is less than $1.0 \%$ considering the improvement of construction efficiency and economic feasibility, although studies on hybrid FRM are somewhat insufficient actually [47-49]. It is thus the ultimate purpose of this study to develop an excellent hybrid FRM that can simultaneously improve the strength and flexural toughness of mortar reinforced with steel-carbon hybrid fibers having different material characteristics with a view to obtain a synergistic effect, which cannot be gained with that of single fibers.

Therefore, this is why, in this study, the mechanical properties, including strength and flexural toughness of single FRM reinforced with either steel or carbon fiber and hybrid FRM reinforced with both steel and carbon fibers, were examined and compared with plain mortar (PM). In addition, after the strength test, the SEM images of the fractured FRM surface were analyzed.

\section{Experimental Program}

2.1. Experimental Plan. In this study, an experimental plan was worked out to evaluate the mechanical properties, including strength and flexural toughness of a single FRM reinforced with only steel or carbon fiber and a hybrid FRM reinforced with steel and carbon fibers. To examine the effect of hybrid, mortar specimens were divided into five levels of mortar mixed and used in the ratio of $100+0 \%, 75+25 \%$, $50+50 \%, 25+75 \%$, and $0+100 \%$ by volume at a total volume fraction of $1.0 \%$ and into plain mortar. For this purpose, 3 cubic specimens were prepared with the size of

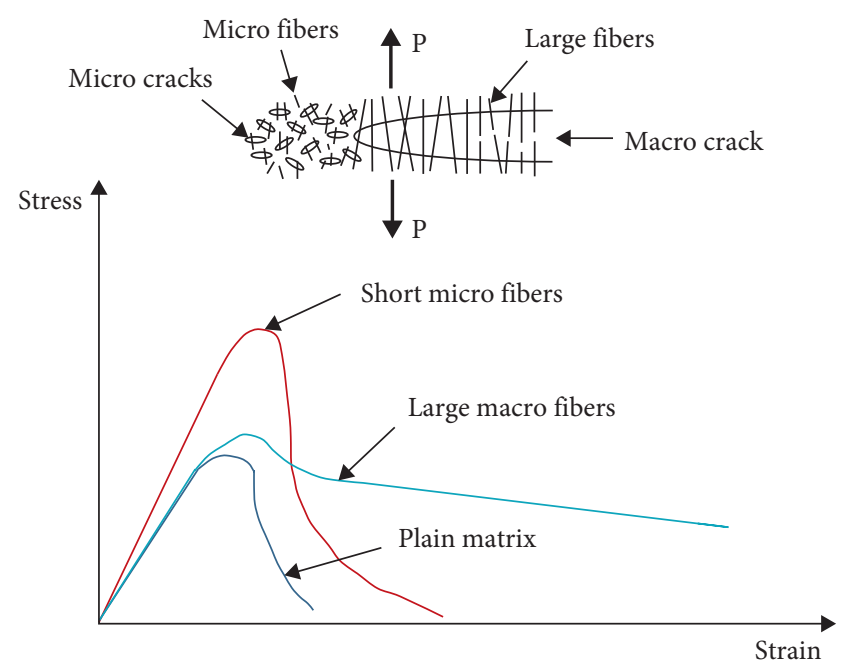

Figure 1: Structures of large and short fibers controlling the crack propagation.

$40 \times 40 \times 160 \mathrm{~mm}$ for a compressive strength test and 3 beam specimens with the size of $100 \times 100 \times 400 \mathrm{~mm}$ for a flexural performance test. For an experimental plan, it was planned to measure the compressive strength at the age of 28 days and to check the flexural toughness and behavior through the flexural performance test. After the strength test, SEM photographs of the fractured single FRM surface and hybrid FRM surface were taken.

2.2. Materials. The cement used in this study was $\mathrm{S}$ company's Ordinary Portland Cement (OPC) type I, with a specific gravity of 3.13 and a specific surface area of $3,860 \mathrm{~cm}^{2} / \mathrm{g}$. For fine aggregate, Jumunjin Standard Sand collected in Jumunjin-eup, Gangneung-si, Gangwon-do, was used to make uniform mortar. The specific gravity of fine aggregate in the surface dry saturated condition was 2.65 . The admixture was a polycarboxylic acid-based product made by D company in Korea, and a light yellow highperformance $\mathrm{AE}$ water-reducing agent with a specific gravity of 1.04 and a $\mathrm{pH}$ of $5.0 \pm 1.5$ was used. The steel fiber used in this study has a diameter of $0.5 \mathrm{~mm}$, a length of $30 \mathrm{~mm}$, and a tensile strength of $1,100 \mathrm{MPa}$. As a steel fiber, the hookedend type made by $\mathrm{K}$ company in Korea with hooks at both ends was used to increase the adhesion to the mortar, and the bundle type made by attaching several strands to each other to facilitate material input was employed. On the other hand, carbon fiber, which was made from raw material of polyacrylonitrile (PAN) by T company in Japan, has a diameter of $0.007 \mathrm{~mm}$ and a length of $6 \mathrm{~mm}$, and its tensile strength and elastic modulus are $4,900 \mathrm{MPa}$ and $230 \mathrm{GPa}$, respectively. In case of carbon fiber, the tensile strength is considerably higher than that of steel fiber, and the fiber length is short, but the aspect ratio is characteristically large. The physical properties of the steel and carbon fibers used in this study are shown in Table 1, and Figure 2 is a photograph taken to show the shape of the fibers used in this study.

Meanwhile, Figure 3 shows a picture of steel fibers and carbon fibers taken using SEM. Figures 3(a) and 3(b) display 
TABle 1: Physical properties of fibers.

\begin{tabular}{lcc}
\hline Properties & Steel fiber $(\mathrm{SF})$ & Carbon fiber $(\mathrm{CF})$ \\
\hline Shape & Hooked-end & Straight \\
Length, $l(\mathrm{~mm})$ & 30 & 6 \\
Diameter, d $(\mathrm{mm})$ & 0.5 & 0.007 \\
Aspect ratio $(l / \mathrm{d})$ & 60 & 857 \\
Density $\left(\mathrm{kg} / \mathrm{m}^{3}\right)$ & 7,850 & 1,800 \\
Tensile strength $(\mathrm{MPa})$ & 1,100 & 4,900 \\
Elastic modulus $(\mathrm{GPa})$ & $>210$ & 230 \\
Elongation $(\%)$ & $>3.5$ & 2.1 \\
\hline
\end{tabular}

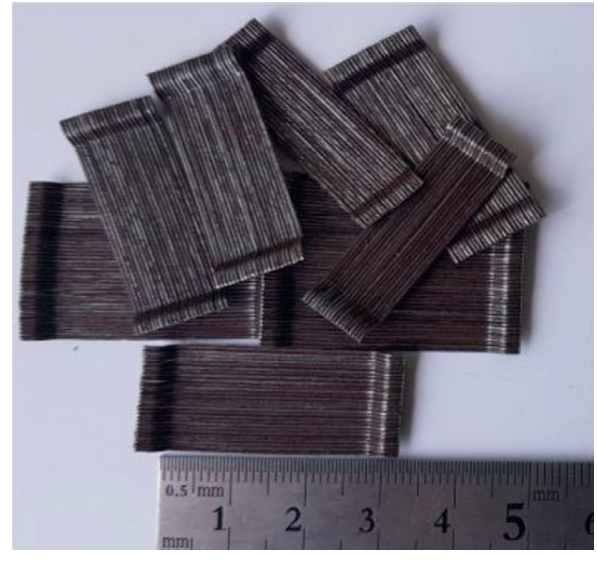

(a)

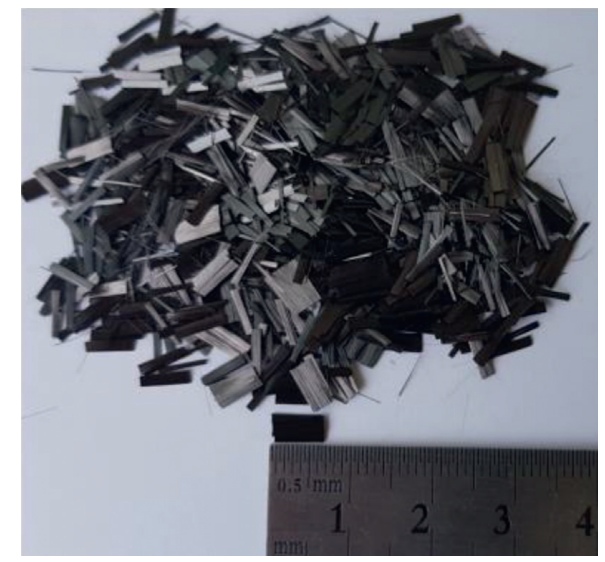

(b)

Figure 2: Pictures of fibers. (a) Steel fibers. (b) Carbon fibers.

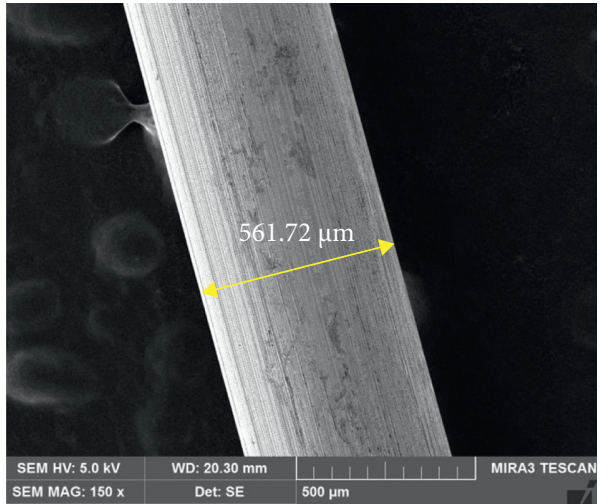

(a)

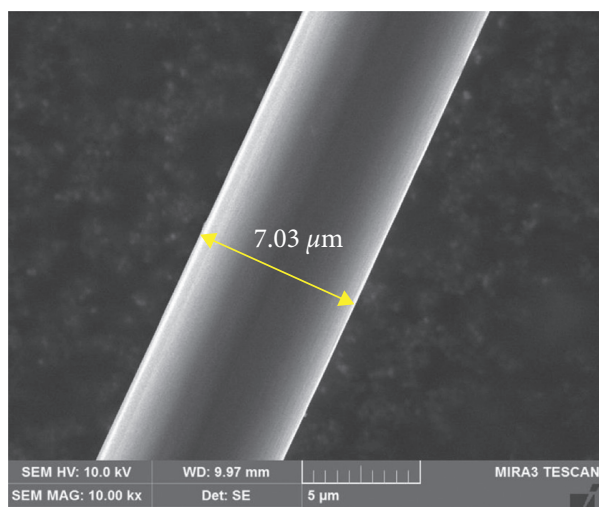

(c)

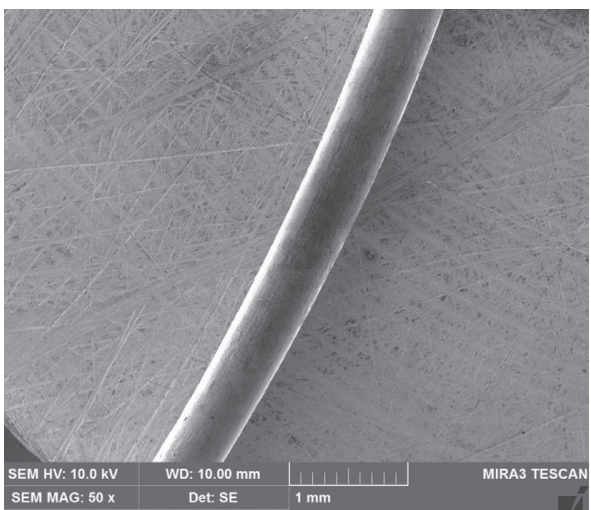

(b)

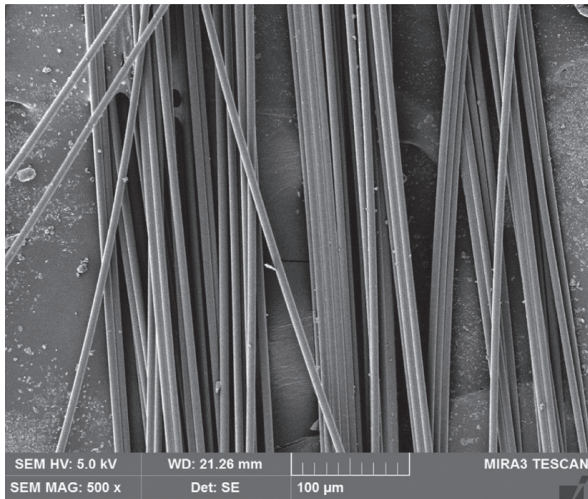

(d)

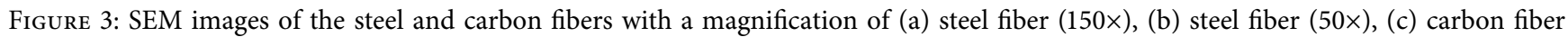
$(10,000 \times)$, and $(d)$ carbon fiber $(500 \times)$. 
SEM pictures taken at 150 times and 50 times magnification of the steel fiber used in this study. As shown in Figure 3(a), the diameter of the steel fiber is about $561.72 \mu \mathrm{m}$, and the fiber surface is somewhat rough. Such rough surface of a steel fiber as seen here is expected to exhibit excellent adhesion performance because it has an effect of increasing adhesion in the cement matrix. However, Figures 3(c) and 3 (d) show the surface morphology photographed at 10,000 times and 500 times magnification of the microcarbon fiber, revealing that as seen in Figure 3(c), the diameter of the carbon fiber is about $7.03 \mu \mathrm{m}$ and surface morphology of fiber is very soft, indicating that the adhesion to the cement matrix is very poor.

2.3. Mix Proportions. Table 2 shows the mortar mix proportions for single fiber and hybrid fiber. The water:cement ratio $(\mathrm{W} / \mathrm{C})$ was set to be 0.46 , and mortar was mixed in a ratio (mass ratio) of cement: standard sand:number of mixtures $=1: 2: 0.46$. The amount of the admixture added was $1.5 \%$ of the mass of cement, and a separate admixture was not used for plain mortar.

2.4. Mixing and Curing Procedure. For preparation of all the plain mortar and FRM specimens, the mortar was first mixed with cement and fine aggregate, and mixture was carried out at a low speed for 30 seconds. To ensure dispersibility of fibers, they were added and mixed further for 90 seconds in a way of dry mixture. Immediately after water and admixture were added, they were mixed for 90 seconds. After stopping mixing for 30 seconds, the adhered mortar was removed, and finally, the blender was operated again to mix at a high speed for 60 seconds. The total mixing time was approximately 5 minutes. After leveling the surface layer to make a uniform mixture, the side of the mold was struck about 30 times with a wooden hammer until the surface was sufficiently compacted without irregularities. After the mortar molds were fabricated, all the specimens were wrapped with a plastic sheet to prevent sudden moisture loss from them. They mold was demolded within 48 hours and kept in a curing water room maintained at $20 \pm 2^{\circ} \mathrm{C}$ for 28 days before testing.

\subsection{Experimental Methods}

2.5.1. Compressive Strength Test. For a compressive strength test, a mold was fabricated according to the test method of KS L ISO 679 [50], and the compressive strength was measured at the age of 28 days. The cured cubic specimens with the size of $40 \times 40 \times 160 \mathrm{~mm}$ was measured for compressive strength using a $100 \mathrm{kN}$ universal testing machine (MTDI Co., Ltd, Korea, UT-100F), and a constant loading speed was applied under the conditions of loading speed of $2400 \mathrm{~N} / \mathrm{s}$.

2.5.2. Flexural Performance Test. For a flexural performance test, the beam specimens with the size of $100 \times 100 \times 400 \mathrm{~mm}$ as stipulated by ASTM C 1609/C 1609/M [51] and by the domestic regulation of KS F 2566 [52] was prepared, and the test was performed all at the age of 28 days. Figure 4 shows the specimen and setup of the test equipment by the thirdpoint loading method for the flexural performance test. To measure the applied load, all the beam specimens were tested for flexural performance using an INSTRON 5597 (EI-F3) universal testing machine. Figure 4(a) shows the geometry of the test specimen and the test setup, and Figures 4(b) and 4(c) show the data measurement system and an example of a deflection measuring device at the loading point, respectively.

The flexural performance test of the beam specimens was applied at third-point loading method, and the deflection and failure load were measured using two linear variable displacement transducers (LVDT) installed at the center of both sides of the specimen. At this time, the deflection rate was controlled at a constant load rate of $0.2 \mathrm{~mm} / \mathrm{min}$ until the specimen was destroyed by displacement control in the range of $1 / 1,500$ to $1 / 3000$ of span length per minute, and the load was measured through a load cell with a capacity of $850 \mathrm{kN}$. By means of the third-point loading method, the flexural strength at the maximum load can be obtained as in

$$
f_{r}=\frac{\mathrm{PL}}{b h^{2}}
$$

where $f_{r}$ is the flexural strength $(\mathrm{MPa}), P$ is the maximum load $(\mathrm{N}), L$ is the span length $(\mathrm{mm}), b$ is the average width of the specimen at the fracture $(\mathrm{mm})$, and $h$ is the average height of the specimen at the fracture $(\mathrm{mm})$.

Flexural toughness, otherwise called energy absorption capacity, is calculated by the total area under the load-deflection curve up to a deflection of $1 / 150$ of the span length as stipulated in ASTM C 1609/C 1609/M [51] and KS F 2566 [52] of the domestic regulation. The total area under the load-deflection curve measured as flexural toughness is calculated from Equation (2) and used to evaluate the equivalent flexural strength. The equivalent flexural strength using third-point loading method is calculated as follows:

$$
f_{r}^{\prime}=\frac{A_{b}}{\delta_{\mathrm{tb}}} \times \frac{L}{b h^{2}},
$$

where $f_{r}^{\prime}$ is the equivalent flexural strength $(\mathrm{MPa}), \delta_{t b}$ is the deflection at $1 / 150$ of the span length $(\mathrm{mm}), L$ is the span length $(\mathrm{mm}), b$ is the average width of the specimen at the fracture $(\mathrm{mm})$, and $h$ is the average height of the specimen at the fracture $(\mathrm{mm}) . A_{b}$ is the area from the load-deflection curve to $\delta_{t b}$. $(\mathrm{J}, \mathrm{kN} \cdot \mathrm{mm})$.

Therefore, the equivalent flexural strength is expressed as the average flexural strength at a given deflection (1/150 of the span length) in the load-deflection curve and is used as an indicator to evaluate the flexural toughness or a loadcarrying capacity by behavior of strain softening or strain hardening after the maximum flexural strength.

\subsubsection{Evaluation Methods of Flexural Performance.} Because there are a lot of difficulties in determining the first crack and measuring accurate deflection in ASTM C 1018 [53] for evaluating flexural performance, this 
TABle 2: Mix proportions of mortar.

\begin{tabular}{|c|c|c|c|c|c|c|c|c|c|}
\hline \multirow[t]{2}{*}{ Mix ID } & \multicolumn{2}{|c|}{$\begin{array}{c}\text { Fiber mix } \\
\text { proportion } \\
\text { by volume } \\
(\%)\end{array}$} & \multirow[t]{2}{*}{ Total volume fraction (\%) } & \multirow[t]{2}{*}{$\mathrm{W} / \mathrm{C}$ ratio } & \multirow[t]{2}{*}{$\mathrm{C} / \mathrm{S}$ ratio } & \multicolumn{3}{|c|}{ Unit weight $\left(\mathrm{kg} / \mathrm{m}^{3}\right)$} & \multirow[t]{2}{*}{$\mathrm{SP}(\mathrm{C} \times \%)$} \\
\hline & SF & $\mathrm{CF}$ & & & & $\mathrm{W}$ & $\mathrm{C}$ & $S$ & \\
\hline $100 \% \mathrm{SF}$ & 100 & 0 & \multirow{6}{*}{1.0} & \multirow{6}{*}{0.46} & \multirow{6}{*}{$1: 2$} & \multirow{6}{*}{297} & \multirow{6}{*}{645} & \multirow{6}{*}{1,290} & \multirow{5}{*}{1.5} \\
\hline $75 \% \mathrm{SF}+25 \% \mathrm{CF}$ & 75 & 25 & & & & & & & \\
\hline $50 \% \mathrm{SF}+50 \% \mathrm{CF}$ & 50 & 50 & & & & & & & \\
\hline $25 \% \mathrm{SF}+75 \% \mathrm{CF}$ & 25 & 75 & & & & & & & \\
\hline $100 \% \mathrm{CF}$ & 0 & 100 & & & & & & & \\
\hline $\mathrm{PM}$ & - & - & & & & & & & - \\
\hline
\end{tabular}

*W/C: water/cement, C/S: cement/sand, SP: superplasticizer, SF: steel fiber, and CF: carbon fiber.

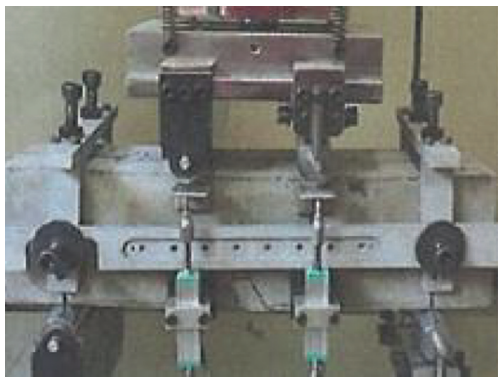

(a)

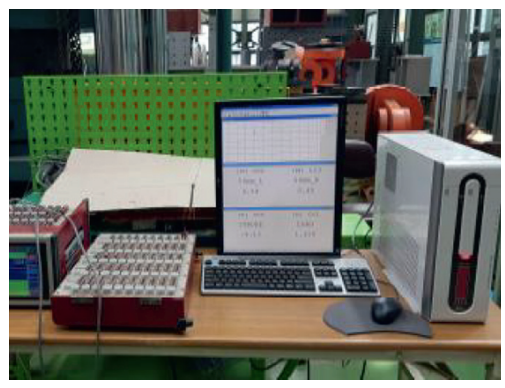

(b)

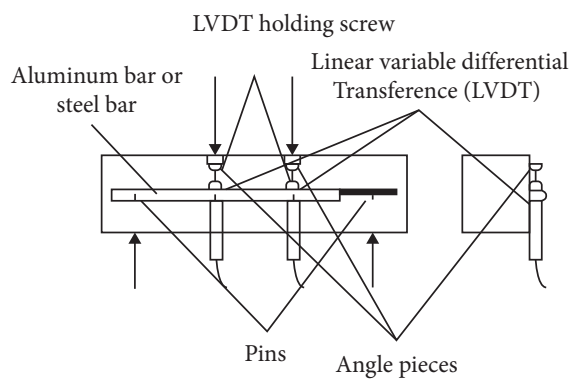

(c)

Figure 4: Testing apparatus of the specimens and setup. (a) Test specimen and setup. (b) Data measurement system. (c) Example of a deflection measuring device at the loading point.

stipulation was replaced with ASTM C 1609/C 1609/M [51] and KS F 2566 [52]. Therefore, in this study, ASTM C $1609 / \mathrm{C} 1609 / \mathrm{M}$ and KS F 2566 [52] were applied to determine flexural performance of FRM. Figure 5 is a diagram presented in ASTM C 1609/C 1609/M [51] and the domestic regulation of KS F 2566 [52], showing the loaddeflection curve to obtain the flexural performance of a beam specimens. As seen in Figure 5, the flexural toughness can evaluate energy absorption capacity by accumulating the sum of the area under the load-deflection curve when the deflection reaches $1 / 600$ and $1 / 150$ of the span length and is expressed as a flexural strength coefficient. In this study, $f_{600}$ and $f_{150}$ were determined by reading the load values of $P_{600}$ and $P_{150}$ from the loaddeflection curve corresponding to the deflection values of $1 / 600$ and $1 / 150$ of the span length and substituting them into the flexural strength equation (1). The flexural toughness of $T_{600}$ was measured at the deflection of $0.5 \mathrm{~mm}$, which is $1 / 600$ of the $300 \mathrm{~mm}$ clear span length, and the flexural toughness of $T_{150}$ was measured at $2.0 \mathrm{~mm}$, which is $1 / 150$ of the $300 \mathrm{~mm}$ clear span length.

2.5.4. SEM Observation. In the present paper, SEM image analysis was performed to observe the fiber distribution state of the fractured FRM surface, and the equipment used was TESCAN's MIRA LMH high-resolution SEM model. The fractured specimens were cut to obtain a surface area of $20 \mathrm{~mm} \times 20 \mathrm{~mm}$ (without affecting the fracture surface), the

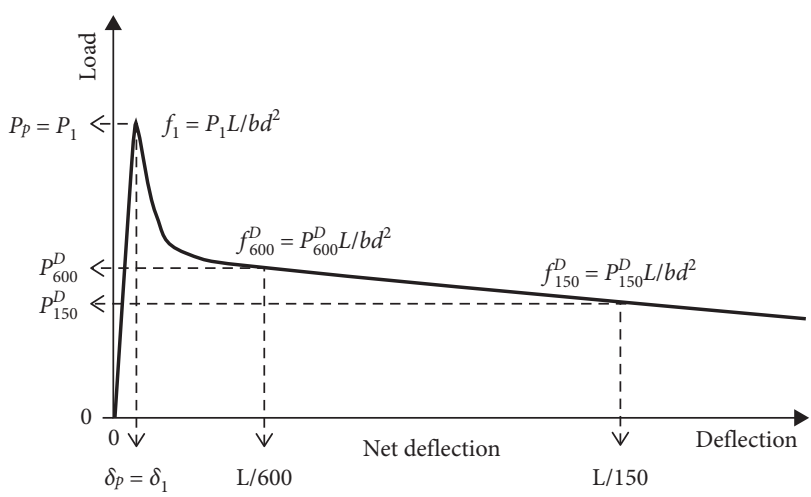

FIgURE 5: Definition of flexural toughness according to ASTM C 1609/C 1609/M and KS F 2566.

test specimens were cleaned and dried; then, the fracture surface was coated with a thin platinum coating (conductive material) and scanned to obtain the images of SEM. In this study, these images are described as the scanning electron micrograph (SEM).

\section{Results and Discussion}

3.1. Compressive Strength. The compressive strength test results of single and hybrid FRM were compared with plain mortar and are summarized in Table 3 and Figure 6. As can be found in Table 3 and Figure 6, the average compressive strength of plain mortar at the age of 28 days was $45.9 \mathrm{MPa}$, 
TABLE 3: Compressive strength test results of FRM and plain mortar.

\begin{tabular}{|c|c|c|c|c|c|c|c|}
\hline \multicolumn{2}{|c|}{$\begin{array}{c}\text { Fiber mix } \\
\text { proportion by } \\
\text { volume }(\%)\end{array}$} & \multirow[t]{2}{*}{ Total volume fraction (\%) } & \multicolumn{4}{|c|}{ Compressive strength at 28 days $(\mathrm{MPa})$} & \multirow[t]{2}{*}{$\%$ increase } \\
\hline SF & $\mathrm{CF}$ & & 1 & 2 & 3 & Ave. & \\
\hline 100 & 0 & & 45.0 & 46.4 & 44.4 & 45.3 & -1.3 \\
\hline 75 & 25 & & 46.1 & 47.5 & 47.1 & 46.9 & 2.2 \\
\hline 50 & 50 & 1.0 & 43.0 & 47.6 & 46.5 & 45.7 & -0.4 \\
\hline 25 & 75 & & 38.6 & 41.4 & 40.7 & 40.2 & -12.4 \\
\hline 0 & 100 & & 37.6 & 33.8 & 35.5 & 35.6 & -22.4 \\
\hline- & - & 0.0 & 47.5 & 44.5 & 45.8 & 45.9 & 0 \\
\hline
\end{tabular}

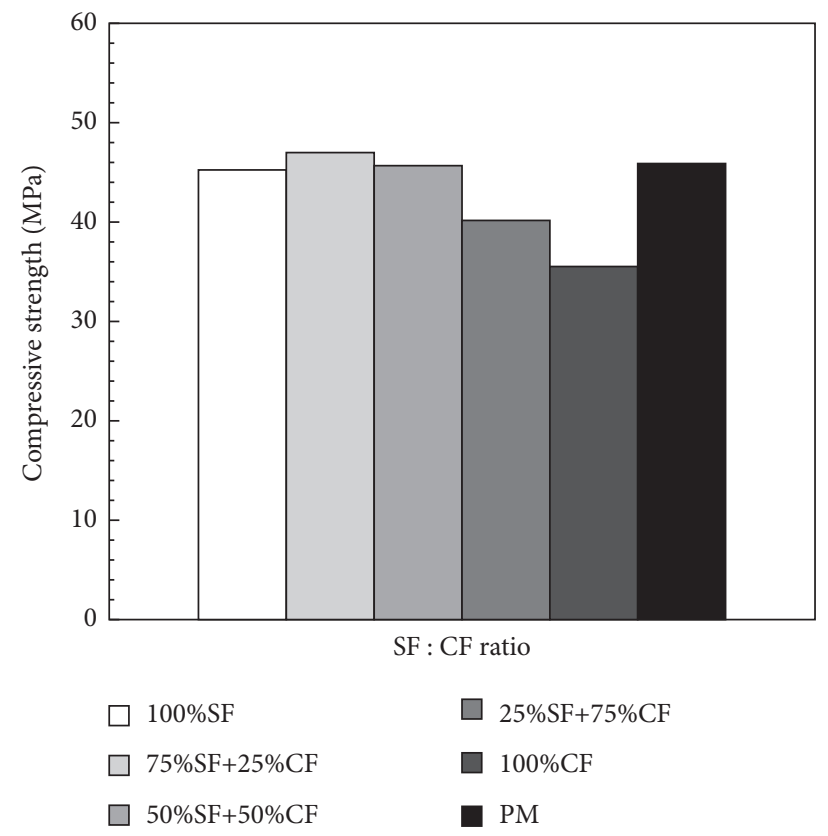

FIgURE 6: Average compressive strength of FRM in different fiber combinations and plain mortar.

and the average compressive strength of a single FRM reinforced with only steel or carbon fibers was measured to be $45.3 \mathrm{MPa}$ and $35.6 \mathrm{MPa}$, respectively. However, the average compressive strength of the hybrid FRM reinforced with $75 \%$ steel fibers $+25 \%$ carbon fibers was $46.9 \mathrm{MPa}$, which was the largest in this experiment. The reason for this increase in the compressive strength was that carbon fibers were used to reinforce the microcarbon fibers, which were relatively small in size compared with steel fibers. As a consequence, all the FRM except for hybrid FRM reinforced with $75 \%$ steel fibers $+25 \%$ carbon fibers showed a somewhat lower compressive strength than plain mortar, and the strength tended to decrease considerably as the carbon fiber increased. The average compressive strength of a single FRM reinforced with carbon fiber alone was $35.6 \mathrm{MPa}$, and as a result, the average compressive strength was significantly reduced by about $22.4 \%$ compared with plain mortar. It is judged that the compressive strength decreased because the interfacial bonding strength between the fibers and matrix in the mortar after hardening was weak due to the nonhydrophilic material on the fiber surface. The results of this kind were also reported in previous studies [54, 55], which pointed out that when a large amount of fiber was used, the dispersibility of fibers decreased, generating in more and more fiber balls as a result, which greatly affected to decrease the compressive strength. In this experiment, therefore, the optimum fiber combination to obtain the maximum compressive strength is $75 \%$ steel fibers $+25 \%$ carbon fibers. Consequently, the hybrid FRM reinforced with $75 \%$ steel fibers $+25 \%$ carbon fibers is considered to be the most appropriate mixing ratio in terms of securing the compressive strength. The percentage increase/decrease in compressive strength of FRM compared with plain mortar is presented in Figure 7.

3.2. Flexural Strength. Table 4 and Figure 8 summarize the flexural strength test results of single FRM and hybrid FRM compared with plain mortar. As shown in Table 4 and Figure 8, the average flexural strength of plain mortar at the age of 28 days was $3.09 \mathrm{MPa}$ and that of a single FRM reinforced with only steel or carbon fibers was measured to 


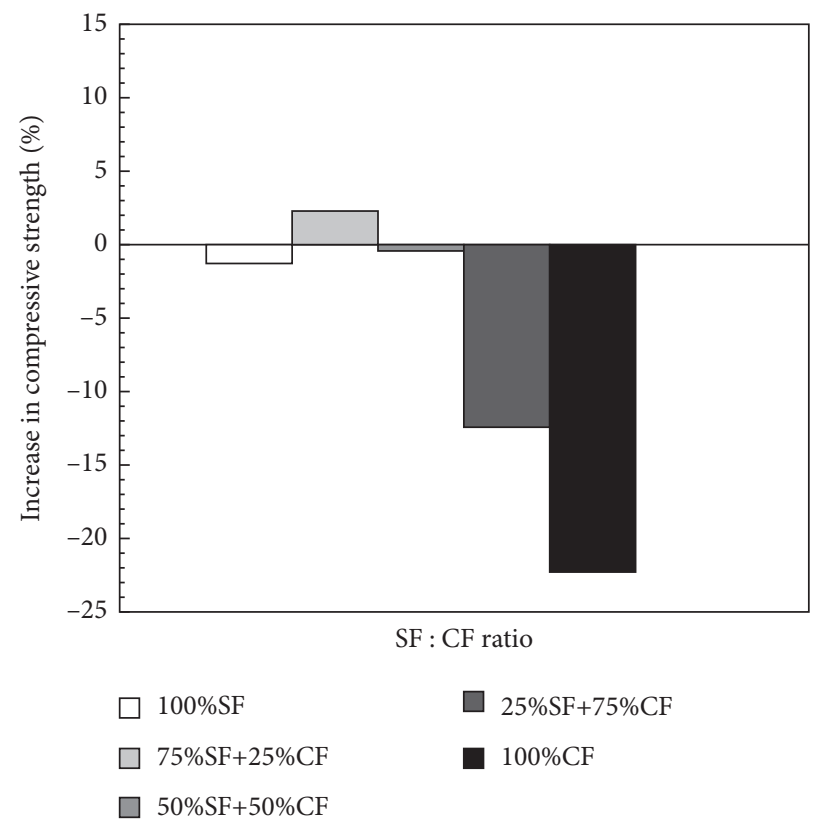

FIgURE 7: Percentage of increase in average compressive strength of FRM over that of plain mortar.

TABLE 4: Flexural strength test results of FRM and plain mortar.

\begin{tabular}{|c|c|c|c|c|c|c|c|}
\hline \multicolumn{2}{|c|}{$\begin{array}{c}\text { Fiber mix } \\
\text { proportion by } \\
\text { volume (\%) }\end{array}$} & \multirow[t]{2}{*}{ Total volume fraction (\%) } & \multicolumn{4}{|c|}{ Flexural strength at 28 days $(\mathrm{MPa})$} & \multirow[t]{2}{*}{$\%$ increase } \\
\hline SF & CF & & 1 & 2 & 3 & Ave. & \\
\hline 100 & 0 & & 5.79 & 5.97 & 5.78 & 5.85 & 89 \\
\hline 75 & 25 & & 8.16 & 7.20 & 7.69 & 7.68 & 149 \\
\hline 50 & 50 & 1.0 & 7.20 & 7.44 & 7.85 & 7.50 & 143 \\
\hline 25 & 75 & & 6.42 & 5.34 & 5.89 & 5.88 & 90 \\
\hline 0 & 100 & & 4.83 & 5.10 & 4.96 & 4.96 & 61 \\
\hline- & - & 0.0 & 2.94 & 3.24 & 3.10 & 3.09 & 0 \\
\hline
\end{tabular}

be $5.85 \mathrm{MPa}$ and $4.96 \mathrm{MPa}$, respectively. The percentage of increase/decrease in flexural strength of FRM compared with plain mortar is presented in Figure 9. The average flexural strength of hybrid FRM reinforced with $75 \%$ steel fibers $+25 \%$ carbon fibers was $7.68 \mathrm{MPa}$, revealing the highest flexural strength, which was an improvement by about $149 \%$ compared with plain mortar. At the same time, the flexural strength of a hybrid FRM reinforced with $75 \%$ steel fibers $+25 \%$ carbon fibers as well as $50 \%$ steel fiber$s+50 \%$ carbon fibers increased by about $31.3 \%$ and $28.2 \%$, respectively, compared with the flexural strength of a single FRM reinforced with only steel fiber. It is considered that the flexural strength is improved by controlling the microcracks of the relatively large fibers, while the short fibers control the microcracks. However, the average flexural strength of a hybrid FRM reinforced with $25 \%$ steel fibers $+75 \%$ carbon fibers was measured to be $5.88 \mathrm{MPa}$, and the average flexural strength of a single FRM reinforced with only carbon fiber showed a little decrease. Such a result as this was also reported in previous studies $[54,55]$, and it is thought because reinforced fibers prevented growth of cracks by playing a crosslinking role and, by thus, improved the flexural strength by means of redistribution of stress. It is possible to obtain a mutual synergy effect of fiber reinforcement by combining macrosteel fibers having large length and diameter with microcarbon fibers having small length and diameter because the flexural strength would increase once fibers are mixed in an appropriate ratio even when the portion of mixed fibers is small. In particular, it is judged that the microcarbon fibers are effectively functioning the role of the microcrack control prior to the maximum load. In this experiment, therefore, the optimum fiber combination to obtain the maximum flexural strength is $75 \%$ steel fibers $+25 \%$ carbon fibers. Consequently, the hybrid FRM reinforced with $75 \%$ steel fibers $+25 \%$ carbon fibers is considered to be the most appropriate mixing ratio in terms of securing the flexural strength.

3.3. Energy Absorption Capacity (Flexural Toughness). The results from flexural toughness measurement of single and hybrid FRM compared with plain mortar are shown in Table 5 and Figure 10. As can be seen from Table 5 and Figure 10, the average flexural toughness of plain mortar the 


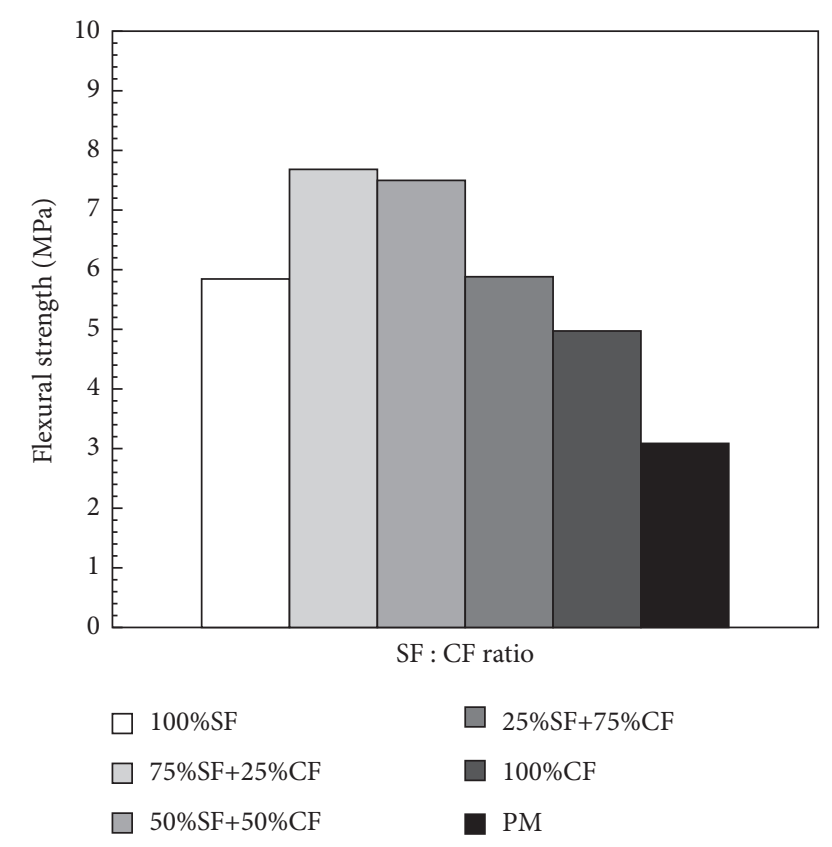

FIGURE 8: Average flexural strength of FRM in different fiber combinations and plain mortar.

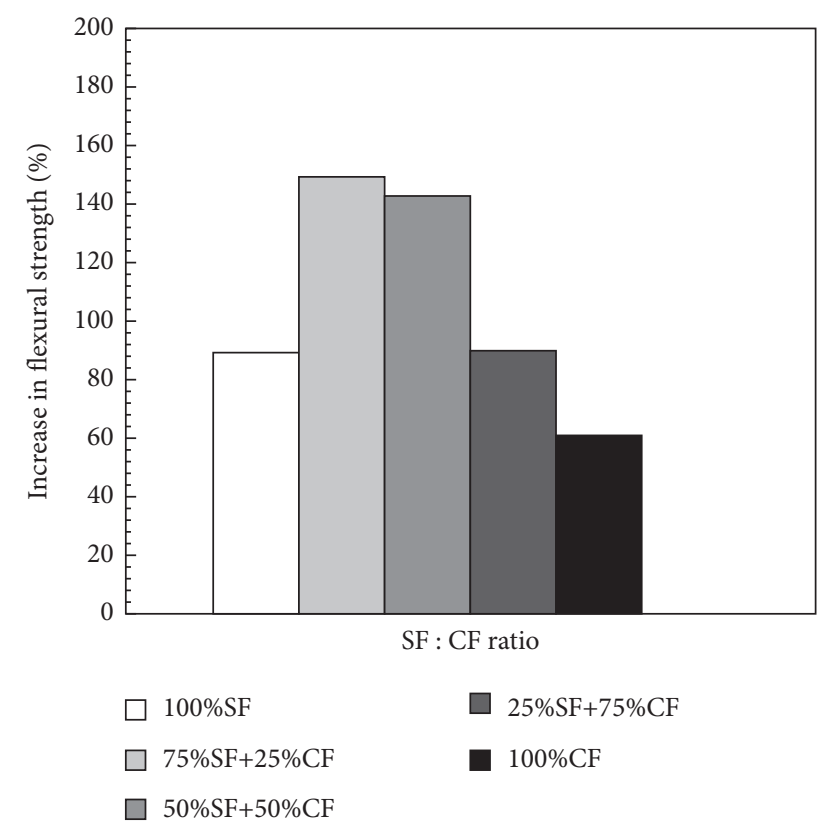

FIgURE 9: Percentage increase in average flexural strength of FRM over that of plain mortar.

age of 28 days was $1.2 \mathrm{~J}$ due to brittle fracture behavior after the maximum load, and the average flexural toughness of a single FRM reinforced with only steel or carbon fiber was measured $27.7 \mathrm{~J}$ and $8.2 \mathrm{~J}$, respectively. On the other hand, the average flexural toughness of a hybrid FRM reinforced with $50 \%$ steel fibers $+50 \%$ carbon fibers was the highest with $32.7 \mathrm{~J}$, and about 27.2 times, 4 times and 1.2 times higher, respectively, compared with plain mortar and a single FRM reinforced with only carbon fiber or steel fiber.
TABLE 5: Flexural toughness measurement results of FRM and plain mortar.

\begin{tabular}{|c|c|c|c|c|c|c|}
\hline \multicolumn{2}{|c|}{$\begin{array}{c}\text { Fiber mix } \\
\text { proportion } \\
\text { by volume } \\
(\%)\end{array}$} & \multirow[t]{2}{*}{$\begin{array}{l}\text { Total volume } \\
\text { fraction }(\%)\end{array}$} & \multicolumn{4}{|c|}{$\begin{array}{l}\text { Flexural toughness at } 28 \text { days } \\
(\mathrm{J})\end{array}$} \\
\hline SF & $\mathrm{CF}$ & & 1 & 2 & 3 & Ave \\
\hline 100 & 0 & & 26.5 & 29.4 & 27.2 & 27.7 \\
\hline 75 & 25 & & 31.7 & 29.3 & 30.1 & 30.3 \\
\hline 50 & 50 & 1.0 & 29.4 & 35.7 & 33.0 & 32.7 \\
\hline 25 & 75 & & 20.4 & 14.6 & 18.4 & 17.8 \\
\hline 0 & 100 & & $(8.3)$ & $(7.9)$ & $(8.4)$ & $(8.2)$ \\
\hline- & - & 0.0 & $(1.4)$ & $(1.0)$ & $(1.2)$ & $(1.2)$ \\
\hline
\end{tabular}

*Values in brackets indicate the value destroyed when the span did not reach $1 / 150(2.0 \mathrm{~mm})$.

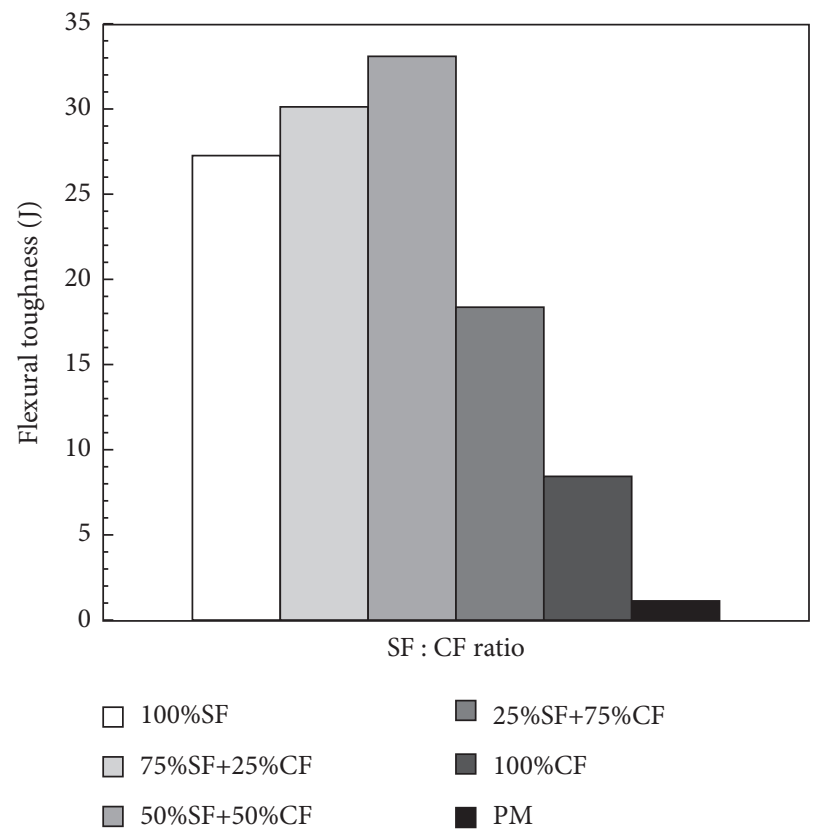

Figure 10: Average flexural toughness of FRM in different fiber combinations and plain mortars.

Compared with plain mortar, all the FRM showed significantly higher flexural toughness. However, the flexural strength of a hybrid FRM reinforced with 75\% steel fiber$s+25 \%$ carbon fibers was the highest, but its flexural toughness was slightly lower due to decrease in the loadcarrying capacity in postcracking strength. On the contrary, the flexural strength of a hybrid FRM reinforced with 50\% steel fibers $+50 \%$ carbon fibers was slightly lower, but its flexural toughness was greatly improved in postcracking strength, indicating that the load-carrying capacity turned out to be the highest. This signifies that the less the amount of microcarbon fiber is used and the more the macrosteel fiber is used, the greater the flexural toughness becomes, ascertaining that the macrosteel fiber has a greater effect on improving the flexural toughness than the microcarbon fiber. In this experiment, therefore, the optimum fiber combination to obtain the maximum flexural toughness is 
$50 \%$ steel fibers $+50 \%$ carbon fibers. As a result, it is judged that the hybrid FRM reinforced with 50\% steel fibers + 50\% carbon fibers is the most appropriate mixing ratio in terms of securing the flexural toughness. Hybrid FRM with such high energy absorption capacity are believed to be much more efficient if properly reinforced for use of the structures requiring dynamic loads, such as earthquake, impact or explosion loads, wind loads, etc.

\subsection{Equivalent Flexural Strength/Ratio and Residual Flexural} Strength/Ratio. The equivalent flexural strength is defined as the average flexural strength at a given deflection (1/150 of the span length) on the load-deflection curve obtained from the flexural performance test. The equivalent flexural strength ratio refers to the value obtained by dividing the equivalent flexural strength by the maximum flexural strength. The residual flexural strength is the flexural strength that the cross section of a specimen can withstand after cracking occurs, and the stress measured at 1/150 of the span length on the load-deflection curve is called the residual flexural strength against deflection. The residual flexural strength ratio means the value obtained by dividing the residual flexural strength by the maximum flexural strength. To obtain the equivalent flexural strength and residual flexural strength, the calculation formula stipulated in ASTM C 1609/C 1609/M [51] and in the domestic regulation KS F 2566 was used [52]. Equation (1) was applied to obtain the maximum flexural strength and residual flexural strength, whereas Equation (2) was employed to get the equivalent flexural strength, which is the average strength up to $2.0 \mathrm{~mm}$ deflection (1/150 of the span length). From these calculations, the average values of equivalent flexural strength/ratio and residual flexural strength/ratio against the maximum flexural strength and residual flexural strength were obtained and compared and are summarized in Table 6. As indicated in Table 6, a single FRM reinforced with only carbon fiber and the plain mortar failed to reach $2.0 \mathrm{~mm}$ of deflection but was fractured due to brittle behavior, whereas a single FRM reinforced with only steel fiber and a hybrid FRM reinforced with steel and carbon fibers were destroyed further than $2.0 \mathrm{~mm}$ from deflection due to the ductile behavior. In particular, the hybrid FRM reinforced with $50 \%$ steel fibers $+50 \%$ carbon fibers demonstrated the highest equivalent flexural strength and equivalent flexural strength ratio, seemingly because, when the initial cracking occurs, the microcarbon fiber bears stress together with the macrosteel fiber and, after reaching the crack strength, the macrosteel fiber alone bears stress, thereby the stress concentration borne by the steel fiber is relieved, which results in higher equivalent flexural strength. The residual flexural strength of a single FRM reinforced with only carbon fiber and the plain mortar could not be obtained, but it has been showed that the residual flexural strength increased highly in case of single FRM reinforced with only steel fiber and hybrid FRM reinforced with $75 \%$ steel fibers $+25 \%$ carbon fibers and with $50 \%$ steel fibers $+50 \%$ carbon fibers. This led us to understand that the macrosteel fiber has a higher crack restriction effect and energy absorption capacity than the microcarbon fiber when the specimen is destroyed. When comparing single FRM and hybrid FRM with plain mortar, both the maximum flexural strength and the equivalent flexural strength showed a tendency to increase significantly, and the equivalent flexural strength of a hybrid FRM reinforced with $50 \%$ steel fibers $+50 \%$ carbon fibers increased about 27.3 times. Meanwhile, the equivalent flexural strength ratio was evaluated as 0.71 for a single FRM reinforced with only steel fiber, and $0.45 \sim 0.65$ for a hybrid FRM reinforced with steel and carbon fibers. Particularly, the equivalent flexural strength ratio was found to be the highest in case of a single FRM reinforced only with steel fiber. On the other hand, in case of a single FRM reinforced with only carbon fiber, the equivalent flexural strength ratio was evaluated as 0.25 , and the plain mortar was evaluated as the lowest with 0.06 . Thus, the reason why the equivalent flexural strength has a smaller value than the maximum flexural strength is because the area under the load-deflection curve is calculated only up to given deflection (1/150 of the span length) as stipulated in the test method of ASTM C 1609/C 1609/M [51] and domestic regulation of KS F 2566 [52]. As can be seen from Table 6, it is judged that applying the equivalent flexural strength is a rather conservative way of evaluation because it receives a predetermined residual load even in the state of deflection by $2.0 \mathrm{~mm}$ or more and has a large amount of flexural toughness.

3.5. Evaluation of Flexural Performance. To find the parameters for flexural performance of beam specimens, several evaluation methods have been developed, and parameters have been obtained using various evaluation methods [51-53, 56]. In this study, the third-point loading method was applied to evaluate the flexural performance of beam specimens in compliance with the test method stipulated in ASTM C 1609/C 1609/M [51] and the domestic standard of KS F 2566 [52]. Table 7 shows the data from comparison and summary of the average flexural performance test result for parameters, such as $P_{600}, P_{150}, f_{600}, f_{150}$, $T_{600}$, and $T_{150}$. As evidenced from Table 7, a relative comparison was difficult due to rapid brittle fracture behavior after initial cracking in case of plain mortar, and deflection was destroyed before it reached $0.5 \mathrm{~mm}$ or $1 / 600$ and $2.0 \mathrm{~mm}$ or 1/150 of the span length. Also, a single FRM reinforced only with carbon fiber was destroyed before reaching $2.0 \mathrm{~mm}$, which is $1 / 150$ of the span length deflection. But in case of a single FRM reinforced with only steel fiber and a hybrid FRM reinforced with steel and carbon fibers, they were destroyed at deflection of more than $2.0 \mathrm{~mm}$. Its flexural toughness at $T_{600}$ turned out to be the lowest with $4.4 \mathrm{~J}$. On the other hand, in case of $50 \%$ steel fibers $+50 \%$ carbon fibers, the flexural toughness at $T_{600}$ and $T_{150}$ was the highest with $8.1 \mathrm{~J}$ and $32.7 \mathrm{~J}$, respectively. After reaching the crack strength, the flexural toughness was greatly improved and the load-carrying capacity was found to be the highest. In case of a single FRM reinforced with only steel fiber, however, the flexural toughness at $T_{600}$ and $T_{150}$ was slightly reduced to $5.5 \mathrm{~J}$ and $27.7 \mathrm{~J}$, respectively. 
TABle 6: Average values of equivalent flexural strength/ratio and residual flexural strength/ratio.

\begin{tabular}{|c|c|c|c|c|c|c|c|}
\hline \multicolumn{2}{|c|}{$\begin{array}{l}\text { Fiber mix } \\
\text { proportion } \\
\text { by volume } \\
(\%)\end{array}$} & \multirow[t]{2}{*}{ Total volume fraction (\%) } & \multirow[t]{2}{*}{$f_{r}(\mathrm{MPa})(1)$} & \multirow[t]{2}{*}{$f_{r}^{\prime}(\mathrm{MPa})(2)$} & \multirow[t]{2}{*}{$f_{r}^{\prime} / f_{r}(2) /(1)$} & \multirow[t]{2}{*}{$R_{r}(\mathrm{MPa})$} & \multirow[t]{2}{*}{$R_{r} / f_{r}(3) /(1)$} \\
\hline SF & $\mathrm{CF}$ & & & & & & \\
\hline 100 & 0 & & 5.85 & 4.15 & 0.71 & 3.42 & 0.59 \\
\hline 75 & 25 & & 7.68 & 4.54 & 0.59 & 3.72 & 0.48 \\
\hline 50 & 50 & 1.0 & 7.50 & 4.91 & 0.65 & 3.45 & 0.46 \\
\hline 25 & 75 & & 5.88 & 2.67 & 0.45 & 1.26 & 0.21 \\
\hline 0 & 100 & & 4.96 & $(1.23)$ & $(0.25)$ & - & - \\
\hline - & - & 0.0 & 3.09 & $(0.18)$ & $(0.06)$ & - & - \\
\hline
\end{tabular}

${ }^{*} f_{r}$ : maximum flexural strength, $f_{r}^{\prime}$ : equivalent flexural strength, $f_{\mathrm{r}}^{\prime} / f_{\mathrm{r}}$ : equivalent flexural strength ratio, $R_{\mathrm{r}}$ : residual flexural strength, and $R_{\mathrm{r}} / f_{\mathrm{r}}$ : residual flexural strength ratio. Values in brackets indicate the value destroyed when the span did not reach $1 / 150(2.0 \mathrm{~mm})$.

TABle 7: Average flexural performance indices using ASTM C 1609/C 1609/M and KS F 2566.

\begin{tabular}{|c|c|c|c|c|c|c|c|c|}
\hline \multicolumn{2}{|c|}{$\begin{array}{c}\text { Fiber mix } \\
\text { proportion } \\
\text { by volume } \\
(\%)\end{array}$} & \multirow[t]{2}{*}{ Total volume fraction (\%) } & \multirow[t]{2}{*}{$P_{600}(\mathrm{kN})$} & \multirow[t]{2}{*}{$P_{150}(\mathrm{kN})$} & \multirow[t]{2}{*}{$f_{600}(\mathrm{MPa})$} & \multirow[t]{2}{*}{$f_{150}(\mathrm{MPa})$} & \multirow[t]{2}{*}{$T_{600}(\mathrm{~J})$} & \multirow[t]{2}{*}{$T_{150}(\mathrm{~J})$} \\
\hline SF & $\mathrm{CF}$ & & & & & & & \\
\hline 100 & 0 & & 18.0 & 12.2 & 5.40 & 3.66 & 4.8 & 27.7 \\
\hline 75 & 25 & & 24.8 & 11.5 & 7.44 & 3.45 & 5.7 & 30.3 \\
\hline 50 & 50 & 1.0 & 23.9 & 13.0 & 7.17 & 3.90 & 6.0 & 32.7 \\
\hline 25 & 75 & & 15.0 & 4.2 & 4.50 & 1.26 & 4.8 & 17.8 \\
\hline 0 & 100 & & 14.0 & - & 4.20 & - & 4.4 & - \\
\hline - & - & 0.0 & - & - & - & - & - & - \\
\hline
\end{tabular}

3.6. Behavior of Load-Deflection Curves. Figure 11 presents the average flexural load-deflection curves of single and hybrid FRM specimens compared with plain mortar specimen. In case of the plain mortar specimen as shown in Figure 11, rapid brittle fracture and flexural crack occurred simultaneously, so that there was little deflection after the maximum load. In the meantime, a single FRM specimen reinforced with carbon fiber only failed to reach a deflection of $2.0 \mathrm{~mm}$ and was destroyed while the stress decreased to a certain level after the maximum load. On the other hand, a single FRM specimen reinforced with only steel fiber and a hybrid FRM specimen reinforced with $75 \%$ steel fibers $+25 \%$ carbon fibers, $50 \%$ steel fibers $+50 \%$ carbon fibers, and $25 \%$ steel fibers $+25 \%$ carbon fibers were all destroyed due to ductile behavior at the deflection of more than $2.0 \mathrm{~mm}$. So, it became evident that as the amount of steel fiber used increases, it still maintains a large amount of flexural toughness even after $2.0 \mathrm{~mm}$ of deflection. This is thought to be because the macrosteel fibers crosslink between the macrocracks and have an excellent effect on the pullout of fibers through adhesion between the fibers and matrix interface.

3.7. A Close Observation under the Flexural Performance Test. Figure 12 shows the close observation results of a typical crack surface for macrocracks in the FRM specimen during the flexural performance test. As shown in Figure 12(a), in case of a single FRM specimen reinforced with only steel fibers, the steel fibers were distributed at very wide intervals along the cracked surface, and a mixture of pullout for steel fibers was observed. On the contrary, in case of a single FRM specimen reinforced with only carbon fibers as shown in Figure 12(b), the carbon fibers were distributed at narrow intervals, and a mixture of pulling and breaking of the carbon fibers was observed. In case of a hybrid FRM specimen reinforced with steel and carbon fibers. Figure 12(c) features that steel fibers are widely distributed along the crack surface, whereas carbon fibers are distributed at narrow intervals. As shown in Figure 12, the fracture mechanism on the crack surface is not merely a breaking of fibers but is pullout phenomenon of fibers caused due to lowered adhesion strength. It is also seen that the crack width is noticeably widened, maintaining a macrocrack. Unlike plain mortar specimens, all the FRM specimens reach macrocracks and failure under load, whereas reinforced fibers restrain cracks and transmitted tensile force to fibers, increasing the strength and letting them reach the maximum load. As a result, fibers began to be pulled out one by one near the tensile area, and the tensile strength gradually decreased. This seems because fibers inhibited the internal cracks that occurred among the cement matrices, and at the same time, they acted as a crosslinking role that transmitted tensile strength across the cracks, thereby inhibiting the growth of cracks.

3.8. Analysis of SEM Images. Figure 13 shows an analysis of SEM images of the fractured single FRM surface and hybrid FRM surface after the strength test. In case of mortar in 


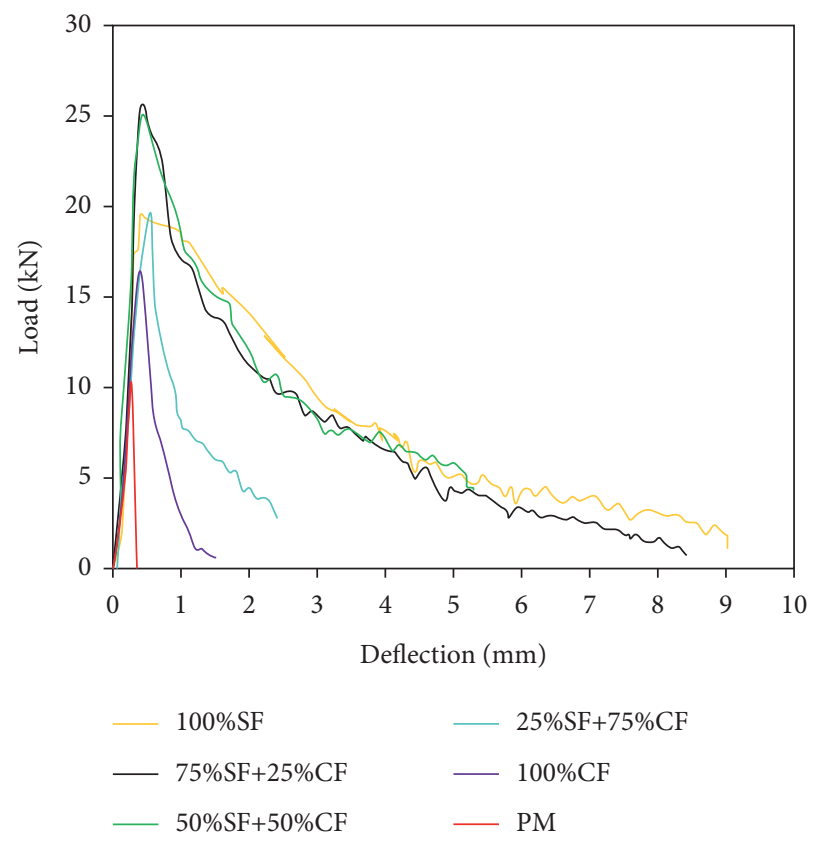

FIGURE 11: Load-deflection curves of single/hybrid FRM and plain mortar specimens.

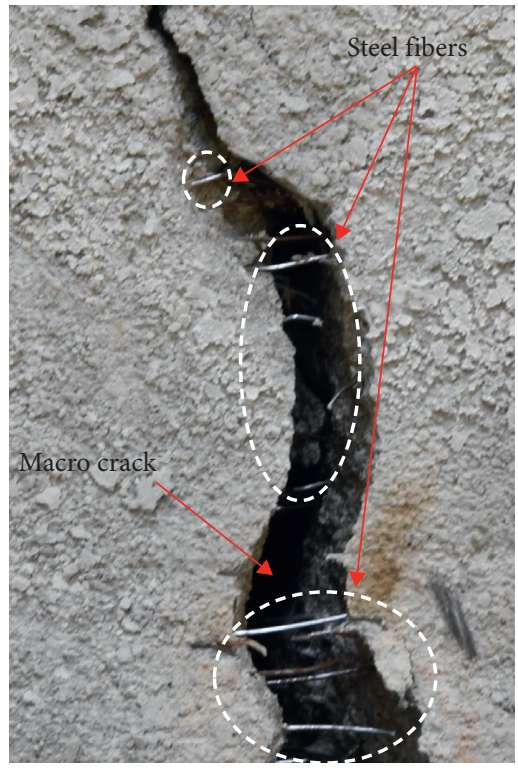

(a)

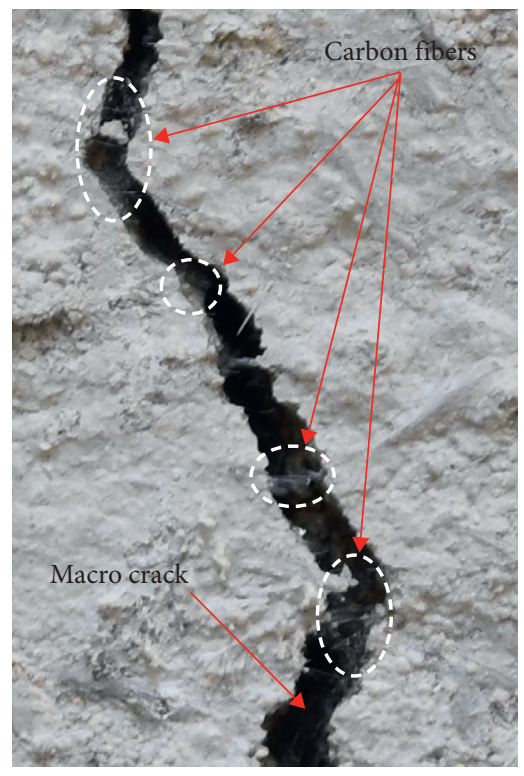

(b)

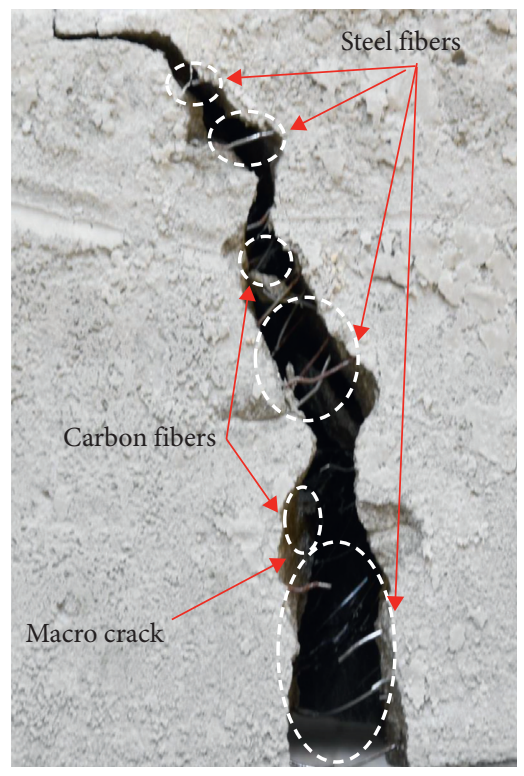

(c)

Figure 12: A close observation of the fiber bridges. (a) Steel fibers. (b) Carbon fibers. (c) Steel and carbon hybrid fibers.

general, the thickness between the aggregate and cement interface is reported to be as high as about $10 \mu \mathrm{m}$ or $50 \mu \mathrm{m}$ at the maximum, and it is reported that the thickness of this interface affects the strength and durability of the mortar $[15,57,58]$. In Figures 13(a) and 13(b), we can observe that large and small cement hydration products of oval shape are formed on the surface of the steel fiber, almost completely covering the entire surface area. It can be seen that the interfacial bonding strength between the fibers and matrix is fairly improved due to formation and increase of the cement hydration products. Relatively C-S-H gel (calcium silicate hydrate-white gel-like hydration product) was observed. For evidence, refer to Figures 13(b) and 13(f). However, as shown in Figures 13(c) and 13(d), it is evident that the surface of carbon fiber in a round circular shape looks very clean and quite smooth. It seems that fiber balling and clumping have occurred because a carbon fiber is difficult to crystallize the cement hydrate and has low affinity, so that the interfacial bonding force between the fibers and matrix is low. Here, we can see pullout and debonding of fibers or transverse cracks 


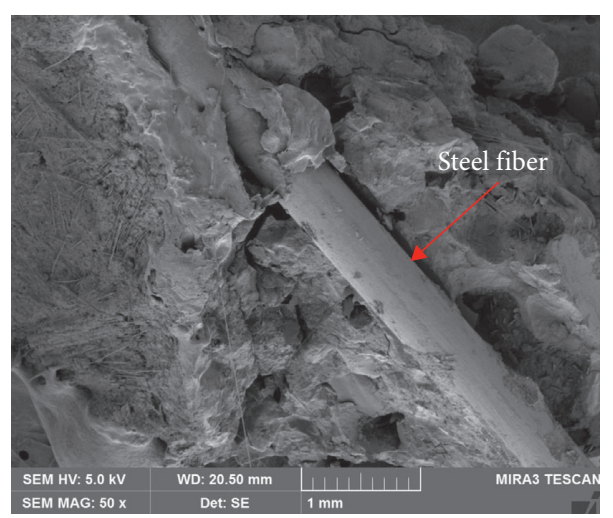

(a)

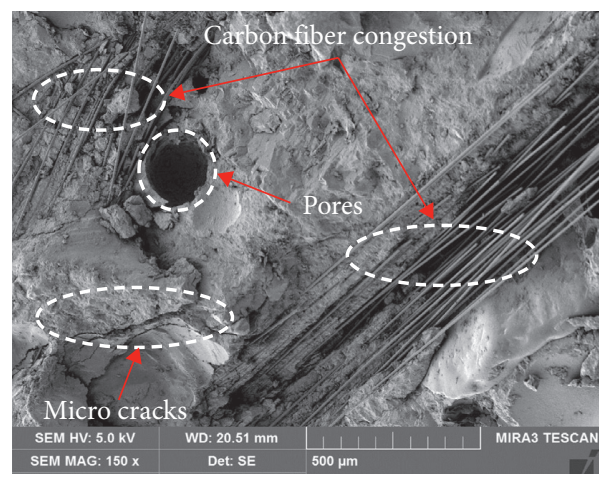

(c)

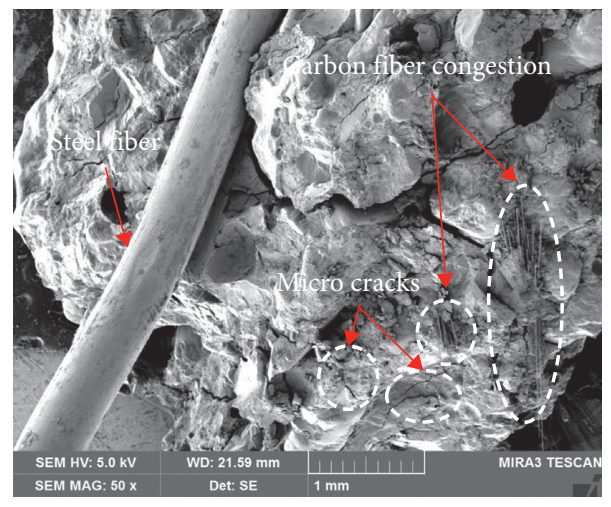

(e)

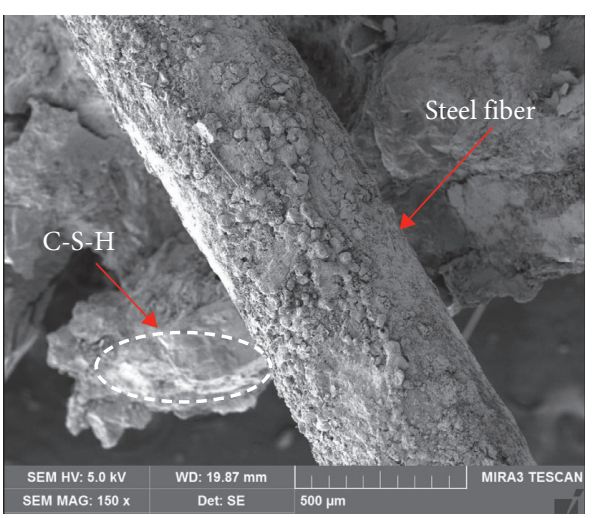

(b)

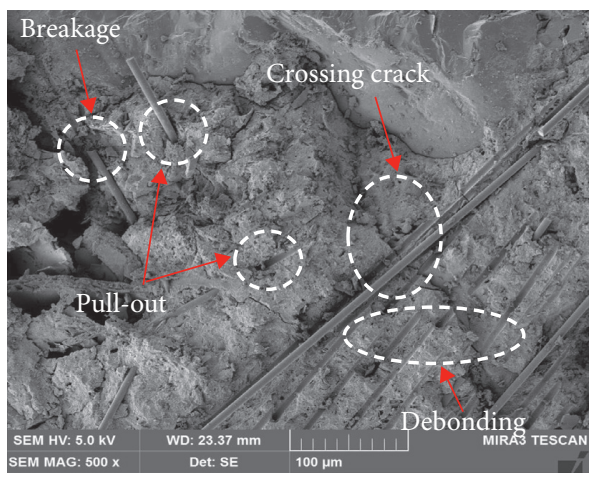

(d)

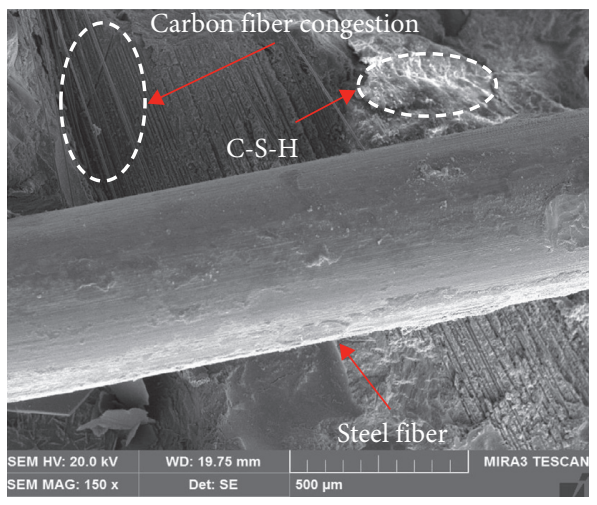

(f)

FIgURe 13: SEM images of the fractured FRM surface with a magnification of (a) steel fiber (50×), (b) steel fiber (150×), (c) carbon fiber

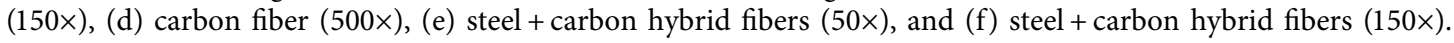

across fibers. As shown in Figure 13(d), all the failure mechanisms were observed, but pullout and debonding of fibers were more predominant. On the other hand, it became obvious that, as shown in Figures 13(e) and 13(f), hybridized fibers form lumps in which carbon fibers are entangled with each other in a thin form like a needle and that the shape of steel fibers is slightly curved in a flexed shape. This phenomenon is judged to be considerably advantageous compared with a single FRM reinforced with only steel fiber or carbon fiber in terms of the interfacial bonding force between the fibers and cement matrix. The reason is because fibers inhibit occurrence and growth of microcracks at the interface between the fibers and cement matrix, and at the same time, fibers suppress occurrence and growth of macrocracks by playing a role of transmitting tensile stress across the cracks through the crosslinking effect of fibers. The failure mechanism of FRM testifies to the fact that such phenomenon as pullout or debonding of fibers is occurring rather than the fiber breakage.

\section{Conclusions}

In this article, the mechanical properties, including strength and flexural toughness of single and hybrid FRM, were examined and compared with plain mortar, and the results might be summarized as follows: 
(1) The hybrid FRM reinforced with $75 \%$ steel fiber$s+25 \%$ carbon fibers showed no significant improvement of compressive strength compared with plain mortar but exerted high improvement in flexural strength by about $149 \%$.

(2) Although the flexural strength of a hybrid FRM reinforced with $50 \%$ steel fibers $+50 \%$ carbon fibers was slightly low, it demonstrated the highest flexural toughness, confirming, furthermore, a synergistic reinforcing effect that improved flexural performance by hybridized steel and carbon fibers.

(3) Compared with plain mortar, both single and hybrid FRM have greatly improved the maximum flexural strength, flexural toughness, and equivalent flexural strength. In particular, it is judged to be a rather conservative evaluation to apply the equivalent flexural strength because it has a predetermined residual load and a large amount of flexural toughness even in the state of deflection of $2.0 \mathrm{~mm}$ or more.

(4) While, in case of plain mortar specimens, the loaddeflection relationship curve showed a strong tendency to brittle fracture behavior, all the FRM specimens displayed stable ductile fracture behavior after the maximum load.

(5) In the analysis of SEM images of the fractured FRM surface, observed was mainly pullout or debonding of fibers. But in case of a single FRM reinforced with only carbon fibers, many carbon fibers got close to each other, resulting in fiber balling and clumping.

We think that, in the future studies, the chemical treatment effect of carbon fibers on the properties of cement composites reinforced with hybrid fibers should be additionally reviewed.

\section{Data Availability}

The data used to support the findings of this study are available from the corresponding author upon request.

\section{Conflicts of Interest}

The authors declare that there are no conflicts of interest regarding the publication of this paper.

\section{Acknowledgments}

This research was supported by Basic Science Research Program through the National Research Foundation of Korea (NRF) funded by the Ministry of Education (Grant no. NRF-2018R1A6A1A03025542). In addition, it was carried out with the support of research funding from Moowang Construction as a joint project with the industry.

\section{References}

[1] F. H. Wittmann, "Effective chloride barrier for reinforced concrete structures in order to extend the service-life,"
Advances in Construction Materials, vol. 2007, pp. 427-437, 2007.

[2] J.-G. Dai, Y. Akira, F. H. Wittmann, H. Yokota, and P. Zhang, "Water repellent surface impregnation for extension of service life of reinforced concrete structures in marine environments: the role of cracks," Cement and Concrete Composites, vol. 32, no. 2, pp. 101-109, 2010.

[3] L. Basheer, J. Kropp, and D. Cleland, "Assessment of the durability of concrete from its permeation properties: a review," Construction and Building Materials, vol. 15, no. 2-3, pp. 93-103, 2001.

[4] E.-H. Yang and V. C. Li, "Strain-rate effects on the tensile behavior of strain-hardening cementitious composites," Construction and Building Materials, vol. 52, pp. 96-104, 2014.

[5] P. Jamsawang, T. Suansomjeen, P. Sukontasukkul, P. Jongpradist, and D. T. Bergado, "Comparative flexural performance of compacted cement-fiber-sand," Geotextiles and Geomembranes, vol. 46, no. 4, pp. 414-425, 2018.

[6] P. Zhang, Y. N. Zho, Q. F. Li, P. Wang, and T. H. Zhang, "Flexural toughness of steel fiber reinforced high performance concrete containing Nano-SiO $\mathrm{S}_{2}$ and fly ash," Advances in Civil Engineering, vol. 2014, Article ID 403743, 11 pages, 2014.

[7] T. K. Tran and D. J. Kim, "High strain rate effects on direct tensile behavior of high performance fiber reinforced cementitious composites," Cement and Concrete Composites, vol. 45, pp. 186-200, 2014.

[8] A. Dehghani and F. Aslani, "The effect of shape memory alloy, steel, and carbon fibres on fresh, mechanical, and electrical properties of self-compacting cementitious composites," Cement and Concrete Composites, vol. 112, pp. 1-16, 2020.

[9] ACI Committee 544, Measurement of Properties of Fiber Reinforced Concrete (Reapproved 2009), 544.2R-89, ACI, Farmington Hills, MI, USA, 2009.

[10] A. E. Naaman, "Toughness, ductility, surface energy and deflection-hardening FRC composites," in Proceedings of the JCI International Workshop on Ductile Fiber-Reinforced Cementitious Composites (DFRCC)-Application and Evaluation (DFRCC-2020), pp. 33-57, Japan Concrete Institute, Tokyo, Japan, October 2002.

[11] A. J. Hamad and R. J. A. Sldozian, "Flexural and flexural toughness of fiber reinforced concrete-American standard specifications review," GRD Journals-Global Research and Development Journal for Engineering, vol. 4, no. 3, pp. 5-13, 2019.

[12] D. J. Kim, A. E. Naaman, and S. El-Tawil, "Comparative flexural behavior of four fiber reinforced cementitious composites," Cement and Concrete Composites, vol. 30, no. 10, pp. 917-928, 2008.

[13] G. H. Heo, J. G. Park, and C. G. Kim, "Evaluating the resistance performance of the VAEPC and the PAFRC composites against a low-velocity impact in varying temperature," Advances in Civil Engineering, vol. 2020, Article ID 7901512, 15 pages, 2020.

[14] V. Corinaldesi, A. Nardinocchi, and J. Donnini, "The influence of expansive agent on the performance of fibre reinforced cement-based compositesfluence of expansive agent on the performance of fibre reinforced cement-based composites," Construction and Building Materials, vol. 91, pp. 171-179, 2015.

[15] M. Safiuddin, M. Yakhlaf, and K. A. Soudki, "Key mechanical properties and microstructure of carbon fibre reinforced selfconsolidating concrete," Construction and Building Materials, vol. 164, pp. 477-488, 2018. 
[16] M. Yakhlaf, M. Safiuddin, and K. A. Soudki, "Properties of freshly mixed carbon fibre reinforced self-consolidating concrete," Construction and Building Materials, vol. 46, pp. 224-231, 2013.

[17] S. Ivorra, P. Garcés, G. Catalá, L. G. Andión, and E. Zornoza, "Effect of silica fume particle size on mechanical properties of short carbon fiber reinforced concrete," Materials \& Design, vol. 31, no. 3, pp. 1553-1558, 2010.

[18] T. Urano, K. Murakami, Y. Mitsui, and H. Sakai, "Study on the size effect of tensile characteristics of carbon fibre-reinforced cement composites," Composites Part A: Applied Science and Manufacturing, vol. 27, no. 3, pp. 183-187, 1996.

[19] Z. Deng, "The fracture and fatigue performance in flexure of carbon fiber reinforced concrete," Cement and Concrete Composites, vol. 27, no. 1, pp. 131-140, 2005.

[20] L. Kanamarlapudi, D. C. K. Jagarapu, and A. Eluru, "Experimental analysis of supplementary cementitious materials with glass fibers," Materials Today: Proceedings, vol. 27, no. 2, pp. 1086-1091, 2020.

[21] S. Mebarkia and C. Vipulanandan, "Compressive behavior of glass-fiber reinforced polymer concrete," Journal of Materials in Civil Engineering, vol. 4, no. 1, pp. 91-105, 1992.

[22] S. T. Tassew and A. S. Lubell, "Mechanical properties of glass fiber reinforced ceramic concrete," Construction and Building Materials, vol. 51, pp. 215-224, 2014.

[23] E. Monaldo, F. Nerilli, and G. Vairo, "Basalt-based fiberreinforced materials and structural applications in civil engineering," Composite Structures, vol. 214, pp. 246-263, 2019.

[24] N. Shafiq, T. Ayub, and S. U. Khan, "Investigating the performance of PVA and basalt fibre reinforced beams subjected to flexural action," Composite Structures, vol. 153, pp. 30-41, 2016.

[25] R. Ralegaonkar, H. Gavali, P. Aswath, and S. Abolmaali, "Application of chopped basalt fibers in reinforced mortar: a review," Construction and Building Materials, vol. 164, pp. 589-602, 2018.

[26] B. Li, L. Xu, Y. Chi, B. Huang, and C. Li, "Experimental investigation on the stress-strain behavior of steel fiber reinforced concrete subjected to uniaxial cyclic compression," Construction and Building Materials, vol. 140, pp. 109-118, 2017.

[27] F. Aslani, L. Hou, S. Nejadi, J. Sun, and S. Abbasi, "Experimental analysis of fiber-reinforced recycled aggregate self-compacting concrete using waste recycled concrete aggregates, polypropylene, and steel fibers," Structural Concrete Journal of the Fib, vol. 20, no. 5, pp. 1-14, 2019.

[28] K. Holschemacher, T. Mueller, and Y. Ribakov, "Effect of steel fibres on mechanical properties of high-strength concrete," Materials and Design, vol. 31, no. 5, pp. 2604-2615, 2014.

[29] M. Mastali and A. Dalvand, "Use of silica fume and recycled steel fibers in self-compacting concrete (SCC)," Construction and Building Materials, vol. 125, pp. 196-209, 2016.

[30] Q. S. Banyhussan, G. Yıldırım, Ö. Anıl, R. T. Erdem, A. Ashour, and M. Şahmaran, "Impact resistance of deflection-hardening fiber reinforced concretes with different mixture parameters," Structural Concrete, vol. 20, no. 3, pp. 1036-1050, 2019.

[31] A. M. Alhozaimy, P. Soroushian, and F. Mirza, "Mechanical properties of polypropylene fiber reinforced concrete and the effects of pozzolanic materials," Cement and Concrete Composites, vol. 18, no. 2, pp. 85-92, 1996.

[32] C. C. Thong, D. C. L. Teo, and C. K. Ng, "Application of polyvinyl alcohol (PVA) in cement-based composite materials: a review of its engineering properties and microstructure behavior," Construction and Building Materials, vol. 107, pp. 172-180, 2016.

[33] G. Yldrm, A. H. Khiavi, S. Yesilmen, and M. Sahmaran, "Selfhealing performance of aged cementitious composites," Cement and Concrete Composites, vol. 87, pp. 172-186, 2018.

[34] P. Zhang, C.-h. Liu, Q.-f. Li, and T.-h. Zhang, "Effect of polypropylene fiber on fracture properties of cement treated crushed rock," Composites Part B: Engineering, vol. 55, pp. 48-54, 2013.

[35] P. Zhang, Q. Li, J. Wang, Y. Shi, Y. Zheng, and Y. Ling, "Effect of nano-particle on durability of polyvinyl alcohol fiber reinforced cementitious composite," Science of Advanced Materials, vol. 12, no. 2, pp. 249-262, 2020.

[36] Y. Wang, V. C. Li, and S. Backer, "Tensile properties of synthetic fiber reinforced mortar," Cement and Concrete Composites, vol. 12, no. 1, pp. 29-40, 1990.

[37] A. M. Brandt, "Fibre reinforced cement-based (FRC) composites after over 40 years of development in building and civil engineering," Composite Structures, vol. 86, no. 1-3, pp. 3-9, 2008.

[38] J.-P. Won, B.-T. Hong, T.-J. Choi, S.-J. Lee, and J.-W. Kang, "Flexural behaviour of amorphous micro-steel fibre-reinforced cement composites," Composite Structures, vol. 94, no. 4, pp. 1443-1449, 2012.

[39] L. R. Betterman, C. Ouyang, and S. P. Shah, "Fiber-matrix interaction in microfiber-reinforced mortar," Advanced Cement Based Materials, vol. 2, no. 2, pp. 53-61, 1995.

[40] G. Yldrm, "Dimensional stability of deflection-hardening hybrid fiber reinforced concretes with coarse aggregate: suppressing restrained shrinkage cracking," Structural Concrete Journal of the Fib, vol. 20, no. 2, pp. 836-850, 2019.

[41] H. R. Pakravan, M. Latifi, and M. Jamshidi, "Hybrid short fiber reinforcement system in concrete: a review," Construction and Building Materials, vol. 142, pp. 280-294, 2017.

[42] N. Banthia and M. Sappakittipakorn, "Toughness enhancement in steel fiber reinforced concrete through fiber hybridization," Cement and Concrete Research, vol. 37, no. 9, pp. 1366-1372, 2007.

[43] N. Banthia and S. M. Soleimani, "Flexural response of hybrid fiber-reinforced cementitious composites," ACI Materials Journal, vol. 102, no. 6, pp. 382-389, 2005.

[44] P. Rashiddadash, A. A. Ramezanianpour, and M. Mahdikhani, "Experimental investigation on flexural toughness of hybrid fiber reinforced concrete (HFRC) containing metakaolin and pumice," Construction and Building Materials, vol. 51, pp. 313-320, 2014.

[45] P. R. Dadash and A. A. Ramezanianpour, "Hybrid fiber reinforced concrete pumice and metakaolin," Civil Engineering Infrastructures Journal, vol. 47, no. 2, pp. 229-238, 2014.

[46] W. Sun, H. Chen, X. Luo, and H. Qian, "The effect of hybrid fibers and expansive agent on the shrinkage and permeability of high-performance concrete," Cement and Concrete Research, vol. 31, no. 4, pp. 595-601, 2001.

[47] J. Feng and Y. Wu, "Research on strength of steel fiber reinforced concrete at low fiber volume fraction based on binary variance analysis," Advanced Materials Research, vol. 742, pp. 243-248, 2013.

[48] B. Ali, R. Kurda, B. Herki et al., "Effect of varying steel fiber content on strength and permeability characteristics of high strength concrete with micro silica," Materials, vol. 13, no. 24, 2020. 
[49] W. Yao, J. Li, and K. Wu, "Mechanical properties of hybrid fiber-reinforced concrete at low fiber volume fraction," $\mathrm{Ce}$ ment and Concrete Research, vol. 33, no. 1, pp. 27-30, 2003.

[50] Korea Agency for Technology and Standards, KS L ISO 679, Methods of Testing Cements-Determination of Strength, Korea Agency for Technology and Standards, Eumseong County, South Korea, 2006.

[51] American Society for Testing Materials, ASTM C 1609/C 1609/M, Standard Test Method for Flexural Performance of Fiber-Reinforced concrete (Using Beam with Third-point Loading), American Society for Testing Materials, West Conshohocken, PA, USA, 2012.

[52] KS F 2566, Standard Test Method for Flexural Performance of Fiber Reinforced concrete, Korea Agency for Technology and Standards, Eumseong County, South Korea, 2014.

[53] ASTM C 1018, Standard Test Method for Flexural Toughness and First Crack Strength of Fiber-Reinforced concrete (Using Beam with Third-point Loading), American Society for Testing Materials, West Conshohocken, PA, USA, 1997.

[54] G. H. Heo, J. G. Park, K. C. Song, J. H. Park, and H. M. Jun, "Mechanical properties of $\mathrm{SiO}_{2}$-coated carbon fiber-reinforced mortar composites with different fiber length and fiber volume fractions," Advances in Civil Engineering, vol. 2020, Article ID 8881273, 12 pages, 2020.

[55] G. H. Heo, J. G. Park, K. C. Song, J. H. Park, and H. M. Jun, "Improving the interfacial bond properties of the carbon fiber coated with a nano- $\mathrm{SiO}_{2}$ particle in a cement paste matrix," Advances in Civil Engineering, vol. 2020, Article ID 8838179, 18 pages, 2020.

[56] Jsce-Sf4, "Method of tests for flexural strength and flexural toughness of steel fiber reinforced concrete," Japan Concrete Institute, vol. 3, pp. 58-66, 1984.

[57] K. Hannawi, H. Bian, W. Prince-Agbodjan, and B. Raghavan, "Effect of different types of fibers on the microstructure and the mechanical behavior of ultra-high performance fiberreinforced concretes fibers on the microstructure and the mechanical behavior of ultra-high performance fiber-reinforced concretes," Composites Part B: Engineering, vol. 86, pp. 214-220, 2016.

[58] K. L. Scrivener, A. K. Crumbie, and P. Laugesen, "The interfacial transition zone (ITZ) between cement paste and aggregate in concrete," Interface Science, vol. 12, no. 4, pp. 411-421, 2004. 